\title{
Multi-objective optimal sizing of distributed generation by application of Taguchi desirability function analysis
}

\author{
Varsha S. Galgali ${ }^{1}$ M. Ramachandran ${ }^{2} \cdot$ G. A. Vaidya $^{3}$
}

(c) Springer Nature Switzerland AG 2019

\begin{abstract}
Distributed Generation (DG) is modular power generating technology. DG has beneficial impact on tail end voltages, line losses and operating cost. The sizing and location of DG in distribution system is a vital undertaking. In this paper Taguchi Desirability Function Analysis (TDFA) is presented. The remarkable highlight of TDFA is the skillful handling of simultaneous optimization of nearly thousand objectives and its ability to generate multiple optimal solutions. It facilitates the effortless addition of each objective. TDFA is used for finding the optimal size of single as well as multiple DG. Size estimation is carried out for multiple objectives of minimizing the line losses, improving the voltage profile and improving voltage stability index (VSI). The objectives may be minimized, maximized or assigned target values simultaneously. In the scope of this paper more than nine objectives have been optimized simultaneously. TDFA has been implemented to determine optimal size of DG for different load conditions. The proposed approach is tested and verified on IEEE 33-bus and IEEE 85 - bus radial distribution system (RDS).
\end{abstract}

Keywords Distributed generation · Radial distribution system ·VSI · TDFA

$\begin{array}{llll}\text { List of symbols } & T_{i} & \text { Target value of response } \\ \mathrm{DG} & \text { Distributed generation } & \mathrm{S}_{1}, \mathrm{~S}_{2}, \mathrm{~S} & \text { Weights } \\ \mathrm{RDS} & \text { Radial distribution system } & w / I m p & \text { Importance value of response } \\ F & \text { No. of input factors } & \mathrm{V}_{\mathrm{B} 1} & \text { Voltage at bus 1 } \\ I & \text { No. of levels } & \mathrm{V}_{\mathrm{B} 2} & \text { Voltage at bus 2 } \\ \mathrm{FFD} & \text { Full factorial design } & \mathrm{R}_{\mathrm{B}} & \text { Line resistance } \\ d f & \text { Degree of freedom } & \mathrm{X}_{\mathrm{B}} & \text { Line reactance } \\ \mathrm{Y} & \text { Response } & \mathrm{I}_{\mathrm{B}} & \text { Line current } \\ \mathrm{R} & \text { No. of responses } & \mathrm{I}_{\mathrm{Bmax}} & \text { Maximum current carrying capacity } \\ x_{1} x_{2} & \text { Input factors } & \mathrm{P}_{\mathrm{LD}} & \text { Active power load connected at bus 2 } \\ B & \text { Regression coefficients } & \mathrm{Q}_{\mathrm{LD}} & \text { Reactive power load connected at bus 2 } \\ \varepsilon & \text { Error term } & \mathrm{P}_{\mathrm{DG}} & \text { Active power injection at bus 2 } \\ 2 \mathrm{FI} & \text { Two-factor interaction } & \mathrm{Q}_{\mathrm{DG}} & \text { Reactive power injected at bus 2 } \\ R^{2} & \text { Coefficient of determination } & \mathrm{P}_{2} & \text { Total active power load at bus 2 } \\ d & \text { Desirability function } & \mathrm{Q}_{2} & \text { Total reactive power load at bus 2 } \\ \mathrm{ID} & \text { Individual desirability } & \mathrm{P}_{\text {loss }} & \text { Real power loss } \\ \mathrm{CD} & \text { Composite desirability } & \mathrm{Q}_{\text {loss }} & \text { Reactive power loss } \\ L_{i} & \text { Minimum acceptable value of response } & \mathrm{P}_{\text {load }} & \text { Total system active power load } \\ U \mathrm{i} & \text { Maximum acceptable value of response } & \mathrm{Q}_{\text {load }} & \text { Total system reactive power load }\end{array}$

$\square$ Varsha S. Galgali, vsgalgali@mescoepune.org | ${ }^{1}$ Modern Education Society's College of Engineering, Pune, India. ${ }^{2}$ MPSTME, SVKM'S NMIMS University, Dhule, India. ${ }^{3}$ Pune Vidyarthi Griha's College of Engg and Technology, Pune, India. 


$\begin{array}{ll}\mathrm{n} & \text { Total no. of responses } \\ \mathrm{nb} & \text { Number of total branches } \\ \mathrm{mb} & \text { Number of total buses } \\ \mathrm{pf}_{-} \mathrm{DG} & \text { Power factor of DG } \\ \mathrm{VSI}_{2} & \text { Voltage stability index at bus 2 } \\ \mathrm{LL} & \text { Lowest limit of response obtained } \\ \mathrm{UL} & \text { Highest limit of response obtained } \\ \mathrm{LW} & \text { Lower weight } \\ \mathrm{UW} & \text { Higher weight }\end{array}$

\section{Introduction}

DG is power generating unit in direct connection with distribution system or load. Recently there is rising interest in DG particularly in context of concern over environmental issues, electricity market restructuring, advanced development in power electronics and essential energy storage devices. DG offers a wide scope of opportunities and has a prime role to play in the modern distribution system. DG offers benefits like loss minimization, improved voltage profile and reliability enhancement of the overall system. Additionally DG will prove to be economically viable with fuel cost cut as well as lowered operation and maintenance cost. Moreover DG provides ancillary services such as reactive power support and frequency control. However integration of DG puts many constraints on distribution system operations. DG will have unfavorable impact on the system parameters if not sized and placed optimally. Such situation frequently results in reverse power flow, increase in fault levels, voltage rise, and harmonic distortion.

Many diverse techniques have been suggested to find optimal location as well as to estimate near optimal DG size for various objectives. The techniques found in the literature can be extensively classified as analytical approaches, numerical methods and heuristic techniques.

Authors have assessed optimal sizing of DG using analytical strategy based on exact loss formula and then most suitable bus for DG placement is found using Fuzzy Expert System [1].The placement and optimal size of DG is evaluated with the objective of congestion management using analytical technique [2]. The optimization of DG type, size and placement in RDS was modeled as a problem of Mixed-Integer Linear Programming (MILP) for minimizing the total investment and operating costs [3]. Authors have implemented Mixed-Integer Nonlinear Programming (MINLP) technique for placement and size formulation of DG [4]. The objective is improvement in the stability margin. Authors have considered probabilistic nature of load as well as renewable DG generation in the work. A feed forward artificial neural network approach is applied to determine the optimal size of DG units [5]. Authors presented Genetic Algorithm (GA) to search for optimal DG allocation [6]. Adel A. et al. proposed Water Cycle Algorithm (WCA) for optimal placement and sizing of DGs and capacitor banks (CBs). Authors optimized a multi-objective function which included minimizing power losses, voltage deviation, total electrical energy cost, total emissions and improving the voltage stability index [7]. A Modified Particle Swarm Optimizer (MPSO) based approach is suggested for placing multiple WPDGs (Wind Power Distributed Generators) optimally along with capacitors [8]. FuzzyGenetic Algorithm (FGA) has been used for simultaneous optimization of various DG parameters [9]. GA-based Tabu Search method (GATS) has been applied for investigating the problem of optimal placement of multi types DG units [10]. A novel meta-heuristic technique Modified Gbest-guided artificial bee colony (MGABC) is used for the multiple objective of power loss reduction, voltage stability improvement and enhancement of voltage level [11]. To identify the ultimate DG location, loss sensitivity analysis (LSA) is used whereas hybrid Artificial Bee Colony and Cuckoo search (ABC-CS) algorithm is implemented for optimal sizing DG [12]. Ant Lion Optimization Algorithm (ALOA) [13] along with LSA has been implemented for deducing optimal sizing and placement of renewable DG. Many other heuristic techniques such as hybrid of $A B C$ and Ant Colony Optimization (ACO) [14], Krill Herd Algorithm (KHA) [15] and Simulated Annealing (SA) [16] have been employed for estimating optimal placement and sizing of DG.

Some of the techniques discussed can handle multiobjective function however addition of each objective leads to complex procedure. None of the techniques cited in the literature have presented multiple near optimal solutions. Taguchi Desirability Function Analysis (TDFA) is presented in this paper. It is an extremely robust statistical tool, which is used extensively in the field of quality control [17]. A combined TDFA and GA approach is utilized to acquire the optimal combination of parameters for manufacturing absorption film required in solar power sector [18]. Taguchi method coupled with the fuzzy logic based desirability function analysis is used for the optimization of bone drilling procedure to limit the drilling induced damage of bone in orthopaedic surgery [19]. Authors have presented TDFA for optimizing of injection moulding process parameters [20]. Taguchi's orthogonal array (TOA) method has been applied for probabilistic load flow studies [21] and state estimation of hybrid power system [22]. To the best of author's knowledge application of TDFA approach for distribution system problem is not found in literature. Contribution of the paper is presentation of TDFA which is remarkably competent in handling complex framework such as power system. TDFA skillfully handles simultaneous optimization of nearly thousand objectives and presents multiple near optimal solutions. 
In this paper the TDFA approach is applied for finding the optimal size of DG with multiple objectives of power loss minimization, improvement of voltage profile, improvement in voltage stability index (VSI) and improvement in power factor of DG. The objectives may be minimized, maximized or assigned target values simultaneously. TDFA is used to compute optimal size of multiple DG for IEEE 33-bus and IEEE 85- bus RDS considering different load conditions. The paper is organized in nine sections. The proposed methodology is introduced in Sect. 2 whereas in Sect. 3 problem formulations are described. The Sect. 4 gives description of test systems used. The Sect. 5 explains the methodology adopted for optimal bus location of DG and implementation of TDFA for optimal sizing of DG is described in Sect. 6. Optimization results are discussed in Sect. 7. The results are validated in Sect. 8 followed by conclusion in Sect. 9.

\section{The proposed methodology:TDFA}

In this paper Design Expert version 10 software is used for implementation of TDFA. TDFA is implemented in four steps viz.

1. Taguchi design of experiments (TDOE)

2. selection of model

3. analysis of responses

4. desirability function analysis (DFA)

\subsection{Taguchi design of experiments (TDOE)}

The optimal sizing of DG is embarked on as an experiment. An experiment is a process which can be divided broadly into three parts as follows.

1. System The system can be considered as the heart of the process. For optimal sizing of DG, the system is a topology of the RDS, incorporating all buses and line data.

2. Input Factors These are variable signals which serve as starting mechanisms of the process. In the scenario considered, input factors are real and reactive power injected by DG and change in load demands.

3. Response Response is nothing but the performance output of the system. Each response constitutes an objective. In this case, responses are the voltage magnitudes at load buses, real power losses, reactive power losses etc.

The design of experiments (DOE) endeavors to plan systematic conduction of experiments in order to acquire data in an intelligent and controlled manner with minimum efforts [23].
Data obtained from DOE provides the information necessary to establish the relationship between specified input factors and the responses of the given process. The possible estimates of input factors are termed as levels. The selection of the input factors, their levels and responses is the most important and critical stage in the implementation. In DOE when all possible combinations of given input factor levels are considered, it is termed as a full factorial design (FFD). The maximum possible combinations in FFD are given by $I^{F}$. Each combination is considered as an experiment/trial/run. Figure 1 shows general model for design of experiments. As shown in Fig. 1, if 4 input factors, each having 5 levels are considered then the total no. of the experiments for FFD are 625. Clearly, conduction of full factorial experiments will be a prohibitive task. Number of experiments required for TDOE is given by equation no. (1).

No. of experiments $=\{(F \times d f)+1\}$

The degree of freedom is statistical term which refers to the no. of parameters that can vary [24] and given by equation no. (2).

$d f=(I-1)$

TDOE reduces the no. of experiment significantly. The example considered earlier will now need only 17 experiments instead of 625 .

\subsection{Selection of model}

An empirical model is selected to establish the relationship that exists between the important design input factors and the response. A regression model is selected in this work. A first order regression model also referred as the main effect model, for two variables is given by equation no. (3).

$Y=\beta_{0}+\beta_{1} x_{1}+\beta_{2} x_{2}+\varepsilon$

The unknown parameter $\beta$ s are estimated from the data acquired from the experiments [23]. Main effect model can be extended by adding two-factor interaction (2F). In such case response will be given by equation no. (4).

$Y=\beta_{0}+\beta_{1} x_{1}+\beta_{2} x_{2}+\beta_{12} x_{1} x_{2}+\varepsilon$

The main effect model needs less no. of experiments than its extension. Each experiment will produce a set of responses. The response values obtained from comparatively few experiments enables response prediction for FFD.

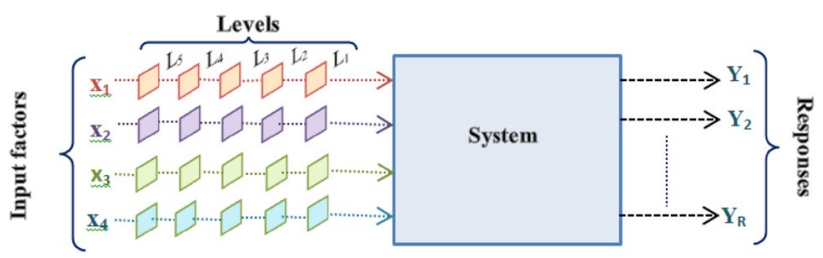

Fig. 1 General model for design of experiments 


\subsection{Analysis of responses}

ANOVA is an efficient statistical tool which is used to interpret experimental data and help decision making. It provides information about how well the chosen model fits the responses. ANOVA supplies information about the effect of the different input factors and their probable interaction as well as the significance of these effects. The $p$ value and $R^{2}$ of model are checked. The $p$-value is a statistical term used for hypothesis testing. The $p$-value less than $5 \%$ indicate a good model whereas the $p$-value below $1 \%$ confirms that the model is highly significant. $R^{2}$ is a measure used for assessing the degree of accuracy with which a model can explain and predict future results. $R^{2}$ closer to 1 shows a good fit between the predicted response value and the actual response value. [25].

\subsection{Desirability Function Analysis (DFA)}

DFA, a well-known multi-response optimization technique, was first implemented by Derringer and Suich [26]. DFA treats each response as an objective and facilitates transformation of complex multi-response problem into a single optimization problem. Assume that there are ' $R$ ' responses, denoted by $Y_{i}(x)$ (where $i=1 \ldots R$ ) which are to be optimized simultaneously. For each response, a desirability function is constructed which is denoted by $d_{i}\left(Y_{j}\right)$ where $d_{i}$ is individual desirability (ID). Depending on the optimization goal set, the three different individual desirability functions may be constructed within an acceptable scope of response values given by (Ui-Li) viz.

1. Target is the best

2. Lower the best

3. Higher the best

These three functions are given by Eqs. (5), (6) and (7) respectively.

1. Target is the best

$d_{i}\left(\hat{Y}_{i}\right)^{\text {target }}=\left\{\begin{array}{lll}\left(\frac{\hat{Y}_{i}(x)-L_{i}}{T_{i}-L_{i}}\right)^{S_{1}} \ldots \text { if } & L_{i} \leq \hat{Y}_{i}(x) \leq T_{i} \\ \left(\frac{\hat{i}_{i}(x)-U_{i}}{T_{i}-U_{i}}\right)^{S_{2}} \ldots \text { if } & T_{i} \leq \hat{Y}_{i}(x) \leq U_{i} \\ 0 \text {... otherwise } & \end{array}\right.$

The exponents $S_{1}$ and $S_{2}$ in Eq. (5) are weights. These weights decide how important it is for $\hat{Y}_{i}(x)$ to be closer to the $T_{i}$. The shape of the desirability function depends on these values hence these exponents are also known as shape constants of desirability function.If the response is required to be in close proximity to the target, the weight can be set to the larger value; otherwise, the weight can be set to the smaller value. Generally the weights are assigned the values in the range from 0.01 to 10 . The response $d_{i}$ $\left(Y_{i}\right)$ equal to zero is indicates highly undesirable response whereas $d_{i}\left(Y_{i}\right)$ of value one signals an ideal or highly desirable response.

2. Lower the best

$d_{i}\left(\hat{Y}_{i}\right)^{\min }=\left\{\begin{array}{l}0 \ldots \text { if } \quad \hat{Y}_{i}(x)>U_{i} \\ \left(\frac{\hat{Y}_{i}(x)-U_{i}}{L_{i}-U_{i}}\right)^{S} \ldots \text { if } \quad L_{i} \leq \hat{Y}_{i}(x) \leq U_{i} \\ 1 \ldots \text { if } \quad \hat{Y}_{i}(x)<L_{i}\end{array}\right.$

The exponent $\mathrm{S}$ in Eq. (6) is the weight which regulates how important it is for $\hat{Y}_{i}(x)$ to be closer to the $L_{i}$. If $\hat{Y}_{i}(x)$ exceeds maximum acceptable value of response then desirability will be equal to zero.

\section{Higher the best}

$d_{i}\left(\hat{Y}_{i}\right)^{\max }=\left\{\begin{array}{l}0 \ldots \text { if } \quad \hat{Y}_{i}(x)<L_{i} \\ \left(\frac{\hat{Y}_{i}(x)-L_{i}}{U_{i}-L_{i}}\right)^{S} \ldots \text { if } \quad L_{i} \leq \hat{Y}_{i}(x) \leq U_{i} \\ 1 \ldots \text { if } \quad \hat{Y}_{i}(x)>U_{i}\end{array}\right.$

If $\hat{Y}_{i}(x)$ is lesser than minimum acceptable value of response then desirability will be equal to zero.Choice of $L_{i}, U_{i}, T_{i}, S_{1}, S_{2}$ and $S$ of is done by investigator.

Once all IDs of ' $R$ ' responses are computed, they are consolidated in a unique function called as composite desirability $(C D)$ as given by Eq. (7).

$C D=\left(\prod_{i=1}^{R} d_{i}^{w_{i}}\right)^{\frac{1}{\Sigma w_{i}}}$

$w_{i}$ is the importance (Imp) of each response relative to the others. In the Design Expert software, the importance, chosen by the analyst, may fluctuate from 1 for the least important response to 5 for the most important one. The $C D$ value is the measure of extent to which the assigned goal has been achieved. Usually this unique function finds more than one combination of input factor levels for which the responses are acceptable. These combinations are nothing but near optimal solutions. The optimal solutions are arranged in the descending order of their $C D$ value. This feature enables TDFA to offer multiple optimal solutions. 


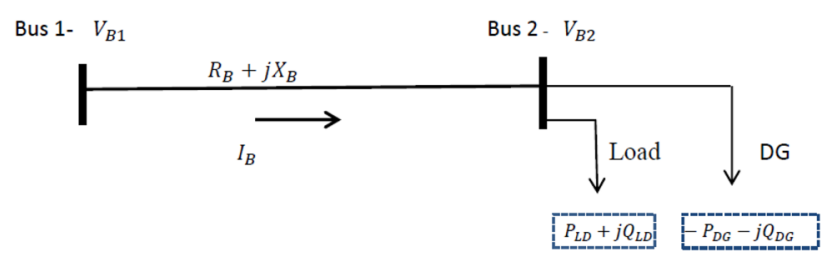

Fig. 2 Two-bus system

\section{Problem Formulation}

The DG contributing real as well reactive power proves more effective for loss reduction than DG contributing real power only.

In this paper, DG is considered to inject both real as well as reactive power at power factor closer to unity. The DG is modeled as negative PQ buses. A simple two- bus network is shown in Fig. 2.

\subsection{Objectives}

1. minimization of real power losses

$$
\operatorname{Min}\left\{P_{\text {loss }}=\sum_{i=1}^{n b}\left|I_{B i}\right|^{2} R_{B i}\right\} i=1,2, \ldots, n b
$$

2. minimization of reactive power losses

$$
\operatorname{Min}\left\{Q_{\text {loss }}=\sum_{i=1}^{n b}\left|I_{B i}\right|^{2} X_{B i}\right\} i=1,2, \ldots, n b
$$

3. voltage profile improvement

$$
\mathrm{V}_{B 2}=\mathrm{V}_{B 1}-I_{B}\left(R_{B}+j X_{B}\right)
$$

4. Voltage stability index (VSI) improvement: A VSI has been proposed [27]. For stable operation of the radial distribution networks $\mathrm{VSI}_{2} \geq 0$ for $\mathrm{n}=2,3 \ldots . . \mathrm{mb}$

$$
\mathrm{VSI}_{2}=\left\{\mathrm{V}_{B 1}\right\}^{4}-4\left\{\mathrm{P}_{2} \mathrm{X}_{B}-\mathrm{Q}_{2} \mathrm{R}_{B}\right\}^{2}-\left\{\mathrm{P}_{2} \mathrm{R}_{B}+\mathrm{Q}_{2} \mathrm{R}_{B}\right\} \mathrm{V}_{B 1}{ }^{2}
$$

5. Pf_DG improvement

Grid code for reactive power injection by DG must be complied. The new standard IEEE P1547-2018 [28] provides more flexibility for DG interconnection.
$\operatorname{Max}\left\{p f_{D G}=\frac{Q_{D G}}{P_{D G}}\right\}$

\subsection{Constraints}

1. real power generation constraint

$$
0 \leq P_{D G} \leq P_{\text {load }}
$$

2. reactive power generation constraint

$$
0 \leq Q_{D G} \leq Q_{\text {load }}
$$

3. voltage constraint

$\left|V_{i}\right| \leq 1 \pm 0.05 p . u$. wherei $=1,2,3 \ldots, m b$

4. line current limit constraint

$I_{B i} \leq I_{B \max } i=1,2, \ldots, n b$

Line current must be less than or equal to maximum current carrying capacity of that branch.

\section{Description of test systems}

The test systems used are IEEE 33 and IEEE 85-bus RDS.

\subsection{IEEE 33-bus RDS}

A single line diagram of IEEE 33-bus, 4369.35 kVA RDS, which has base active and reactive load of $3715 \mathrm{~kW}$ and 2300 kVAR [29] respectively, is shown in Fig. 3. The IEEE 33-bus RDS without DG has real and reactive power losses of $210.07 \mathrm{~kW}$ and $142.44 \mathrm{kVAR}$ respectively.

\subsection{IEEE 85-bus RDS}

The Fig. 4 shows a single line diagram of IEEE 85-bus, 3638.71 kVA RDS, which has base active and reactive load of $2550.56 \mathrm{~kW}$ and $2595.16 \mathrm{kVAR}$ [30] respectively. The IEEE 85 -bus RDS without DG has real and reactive power losses of $313.24 \mathrm{~kW}$ and $196.11 \mathrm{kVAR}$ respectively.

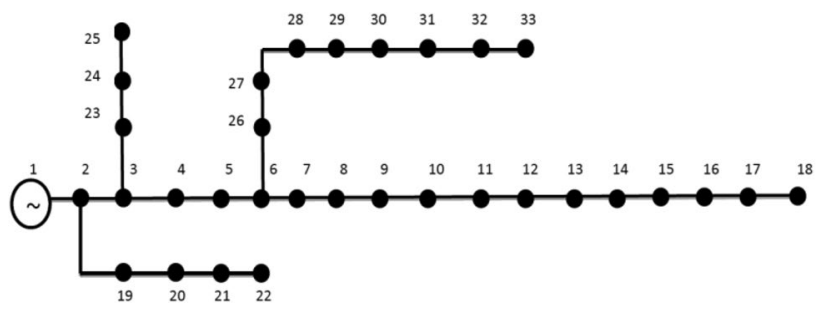

Fig. 3 Single line diagram of IEEE 33-bus RDS 


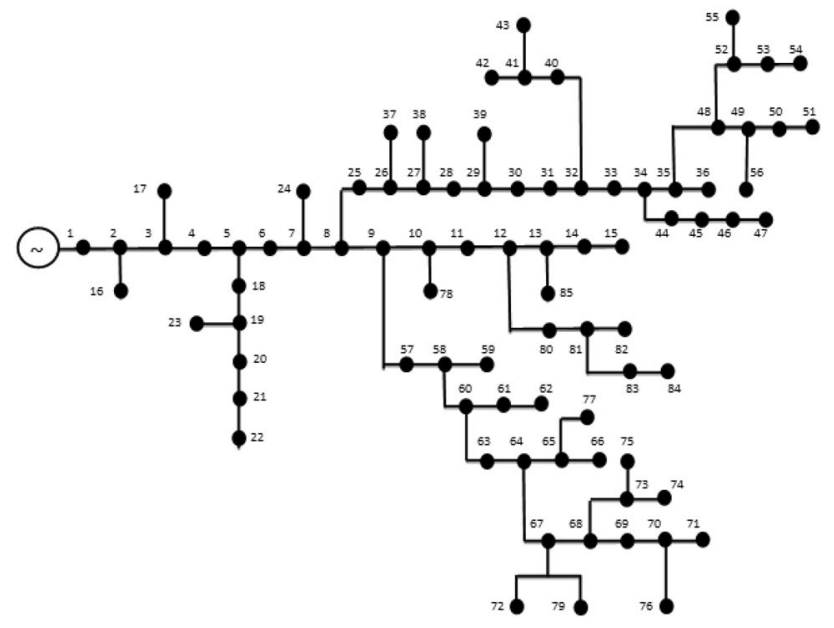

Fig. 4 Single line diagram of IEEE 85-bus RDS

Table 1 Optimal bus selection

\begin{tabular}{llll}
\hline Test systems & Bus no. & VSI & Voltage (p.u.) \\
\hline IEEE 33-bus & $\mathbf{1 8}$ & $\mathbf{0 . 6 6 8}$ & 0.904 \\
& 17 & 0.670 & 0.905 \\
& 16 & 0.676 & 0.907 \\
IEEE 85-bus & $\mathbf{5 4}$ & $\mathbf{0 . 5 8 7}$ & 0.908 \\
& 53 & 0.588 & 0.909 \\
& 55 & 0.588 & 0.909 \\
\hline
\end{tabular}

The values in bold signify the bus chosen for 1 DG placement and its VSI value

\section{Determination of Optimal bus location for DG}

In this paper candidate buses are identified using VSI for reducing search space for optimal location. The bus having the lowest VSI value is the most sensitive to voltage collapse and is chosen as candidate bus for DG placement. A MATLAB program is prepared for computing losses, bus voltages and VSI of test systems. For each test system, three buses having the minimum VSI are identified after arranging them in an ascending order and same three buses have the minimum voltage as well. These three buses along with their VSI and voltage values are given in Table 1. In case of 1 DG placement bus no. 18 is selected for IEEE 33-bus RDS whereas bus no. 54 is chosen for IEEE 85 -bus RDS. The values of VSI for all buses are recalculated after placement of first DG and bus having lowest VSI is identified for placement of second DG. The same procedure is followed for placement of next DG.

\section{Selection of input factors}

- Input factors should influence response

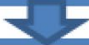

2. Determination no.of levels

- Minimum two levels for each input factor

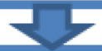

3. Assigning values to the level

- Level value should not be repeated

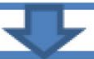

4. Selection of responses or objectives

- Maximum 999 objectives

\section{Application of TDOE and conduction of} experiments

- Select model and calculate number of experiments. Refer eq.no. (1) - (4)

- One experiment constitutes to a load flow for given set of input factors

- Compute response values

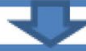

6. Analysis of responses

- Conduct ANOVA

7. Simultaneous optimization

- Set the parameter constraint

- Maximum 999 objectives can be minimized, maximized or assigned target value simultaneously. Refer eq. no. (5) - (7)

- Multiple optimal solutions arranged according to $C D$ values. Refer eq. no. (8)

Fig. 5 Steps for implementation of TDFA

Table 2 Input factors and their level values

\begin{tabular}{lllll}
\hline Level no. & $\begin{array}{l}\mathrm{P}_{\text {load }} \\
(\mathrm{kW})\end{array}$ & $\begin{array}{l}\mathrm{Q}_{\text {load }} \\
(\mathrm{kVAR})\end{array}$ & $\begin{array}{l}\mathrm{P}-\mathrm{DG} @ 18 \\
(\mathrm{~kW})\end{array}$ & $\begin{array}{l}\text { Q-DG@18 } \\
(\mathrm{kVAR})\end{array}$ \\
\hline 1 & 3715.00 & 2300.00 & 557.25 & 115.00 \\
2 & 3752.15 & 2323.00 & 668.70 & 184.00 \\
3 & 3789.30 & 2346.00 & 780.15 & 253.00 \\
4 & 3826.45 & 2369.00 & 891.60 & 322.00 \\
5 & 3863.60 & 2392.00 & 1003.05 & 391.00 \\
6 & 3900.75 & 2415.00 & 1114.50 & 460.00 \\
\hline
\end{tabular}




\section{Implementation of TDFA for optimal sizing of DG}

Implementation of TDFA for DG placement is carried out following the seven step procedure given in Fig. 5 . Detailed description of implementation of approach for 1 DG placement for IEEE 33-bus is given here

Table 2 shows the inputs factors chosen viz. (i) total real power load $\left(\mathrm{P}_{\text {load }}\right)$ in $\mathrm{kW}$ (ii) total reactive power load $\left(\mathrm{Q}_{\text {load }}\right)$ in kVAR (iii) real power injected by DG at bus18(PDG@18) in kW (iv) reactive power injected by DG at bus 18 (Q-DG@18) in kVAR. The next step is to determine the no. of levels and assign level value to each

factor. Four input factors and their respective level values are shown in the Table 2.

All four factors have six levels each. The first level of $\mathrm{P}_{\text {load }}$ is its base value and subsequent levels are incremented in steps of $1 \%$ of base value. The $Q_{\text {load }}$ level values are assigned following similar pattern. The first level of P-DG@18 is 15\% of base $P_{\text {load }}$ and subsequent levels are incremented in steps of $3 \%$ of base $P_{\text {load }}$. The first level Q-DG@18 is 5\% of base $\mathrm{Q}_{\text {load }}$ and subsequent levels are incremented in steps of 3\% of base $\mathrm{Q}_{\text {load. }}$. It should be noted that it is not mandatory to increment the level values

in uniform steps.

The lowest and highest possible kVA injection by DG would be 568.99 and 1205.70 respectively. The level values are entered in randomized factorial design chosen for carrying out the experimentation. Then next step is response selection. As mentioned earlier each response is treated as an objective. There is a provision for 999 responses to be minimized, maximized or assigned target value simultaneously. This remarkable feature enables TDFA to simultaneously optimize losses, voltages of all buses and VSI of all buses. However for simplicity nine responses have been simultaneously optimized. Response parameters chosen here are i) real power losses $\left(P_{\text {loss }}\right)$ in $\mathrm{kW}$ ii) reactive power losses $\left(\mathrm{Q}_{\text {loss }}\right)$ in kVAR iii) voltage at bus 16 (V@16) in p.u iv) voltage at bus 17 (V@17) in p.u v) voltage at bus 18 (V@18) in p.u vi) VSI at bus 16 (VSI@16) vii) VSI at bus 17 (VSI @17) viii) VSI at bus 18 (VSI@18) ix) power factor of DG (pf_DG).

For the no. of input factors and levels considered, FFD will require $6^{4}$ i.e. 1296 experiments. TDOE is applied to reduce the no. of experiments. Hence for considering only main effects of the factors, no. of experiments required is 21 whereas if $2 F /$ is to be studied, the no. of experiments required is 171. Five experiments are suggested as a lack of fit. In this paper $2 \mathrm{Fl}$ model is selected. Therefore conduction of total 176 experiments is required.

A load flow calculation for a combination of given input factor levels corresponds to an experiment. The response values for each combination are obtained using MATLAB
Table 3 Parameter settings

\begin{tabular}{|c|c|c|c|}
\hline Parameter & LL/UL & LW/UW & $\operatorname{Imp}$ \\
\hline \multicolumn{4}{|l|}{ Input factors } \\
\hline 1. $P_{\text {load }-}$ set $=3715$ & $3715 / 3900.75$ & & \\
\hline 2. $Q_{\text {load- }}$ set $=2300$ & $2300 / 2415$ & & \\
\hline 3.P-DG@18-in range & $557.25 / 1114.5$ & & \\
\hline 4. Q-DG@18-in range & $115 / 460$ & & \\
\hline \multicolumn{4}{|l|}{ Reponses or objectives } \\
\hline 1. $P_{\text {loss- }}$ minimize & $126.08 / 156.25$ & $-/ 1$ & 3 \\
\hline 2. $\mathrm{Q}_{\text {loss-minimize }}$ & $87.06 / 105.99$ & $-/ 1$ & 3 \\
\hline 3. V@16-target=1 & $0.948 / 1.002$ & $1 / 1$ & 3 \\
\hline 4. V@17-target=1 & $0.952 / 1.015$ & $1 / 1$ & 3 \\
\hline 5. V@18-target=1 & $0.955 / 1.021$ & $1 / 1$ & 3 \\
\hline 6.VSI@16-target=1 & $0.808 / 1.009$ & $1 / 1$ & 3 \\
\hline 7.VSI@17-target=1 & $0.822 / 1.058$ & $1 / 1$ & 3 \\
\hline 8. VSI@18-target=1 & $0.831 / 1.085$ & $1 / 1$ & 3 \\
\hline 9. pf_DG-maximize & $0.771 / 0.995$ & $1 /-$ & 3 \\
\hline
\end{tabular}

program and are fed into the design for further analysis. For each response, an ANOVA is carried out. After analyzing responses of 176 experiments, LL as well UL of all responses are obtained and are shown in Table 3. The exponents in Eqs. (5)-(7) are referred as LW and UW in Design expert. LW, UW and Imp of all responses can be varied as per requirement.

\section{Optimization results and discussion}

\subsection{IEEE 33-bus RDS}

\subsubsection{One DG placement}

The parameter setting is shown in Table 3. When parameter is set equal to any level only that level is available to be used in optimal solution. But when it is set in range any level of that parameter can be chosen. When all the input factors shown are set in range then total $6^{4}$ i.e. 1296 solutions would be available arranged in the descending order of respective $C D$ values. The input factors $P_{\text {load }}$ and $\mathrm{Q}_{\text {load }}$ are set equal to their base values whereas P-DG@18 and Q-DG@18 are set to in range. Then effectively six levels of only two factors i.e.P-DG@18 and Q-DG@18 are available. Under these settings total $6^{2}$ i.e. 36 solutions would be available. $P_{\text {loss }}$ and $\mathrm{Q}_{\text {loss }}$ are to be minimized. The three bus voltages are assigned the target of $1.0 \mathrm{p.u}$ as its UL is more than 1 . Similarly VSI at three buses are assigned the target of 1. Response pf_DG is to be maximized. All responses are given importance of 3 . LW and UW are set to 1 . 


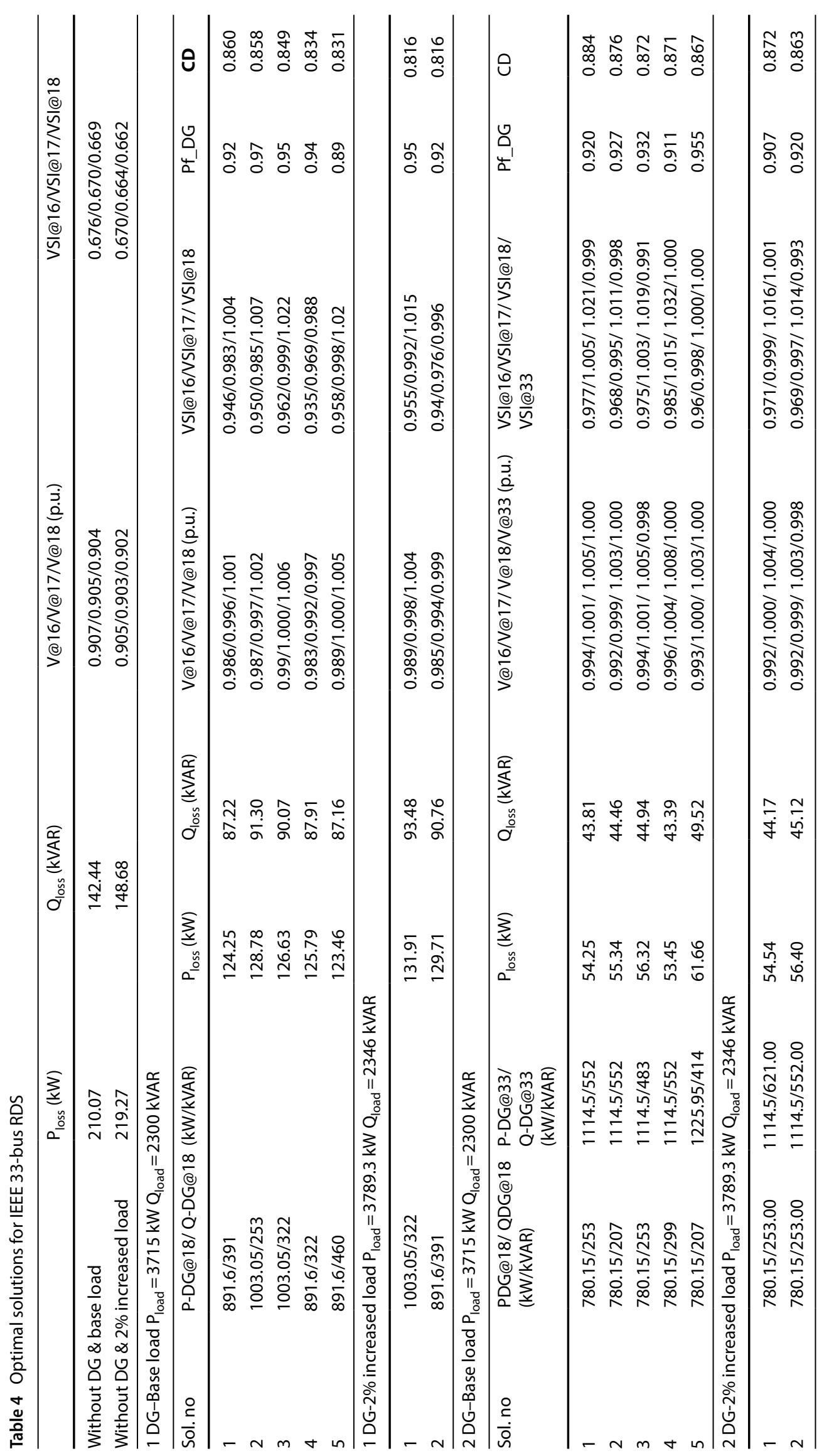


Out of these 36 solutions first 5 solutions are given in Table 4. The first solution for the base load, P-DG@18 and Q-DG@18 of size of $891.6 \mathrm{~kW}$ and 391 kVAR respectively has the highest $C D$ value of 0.86 .The $P_{\text {loss }}$ and $Q_{\text {loss }}$ are $124.25 \mathrm{~kW}$ and $87.22 \mathrm{kVAR}$ respectively. The voltages V@16, V@17 and V@18 are improved to 0.986, 0.996 and 1.001 respectively. Similarly VSI@16, VSI@17 and VSI@18 are improved to $0.946,0.983$ and 1.004 respectively with pf_DG of 0.92 . The ID values of responses are not shown here.

Figure 6 shows $C D$ as well as ID variation of responses for first 5 solutions given in Table 4. It should be noted that the fifth solution has $\mathrm{P}_{\text {loss }}$ and $\mathrm{Q}_{\text {loss }}$ lesser than first solution whereas V@16, V@17, VSI@16 and VSI@17 are

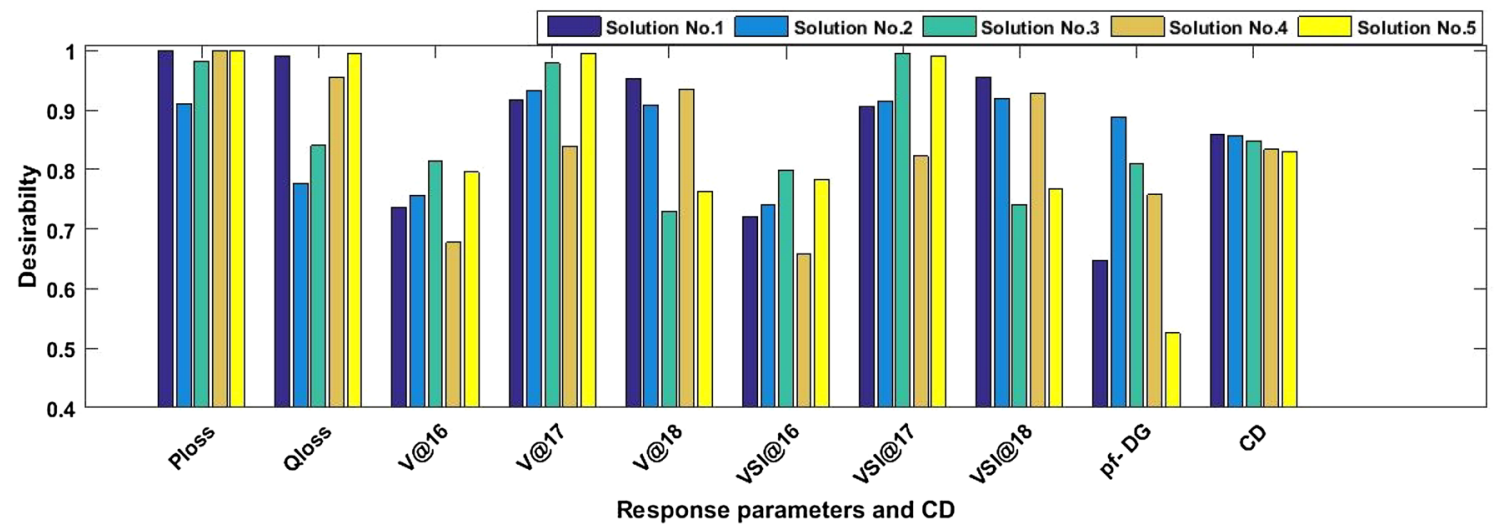

Fig. 6 CD and ID value values of responses for first 5 solutions for IEEE 33 BUS - 1DG placement

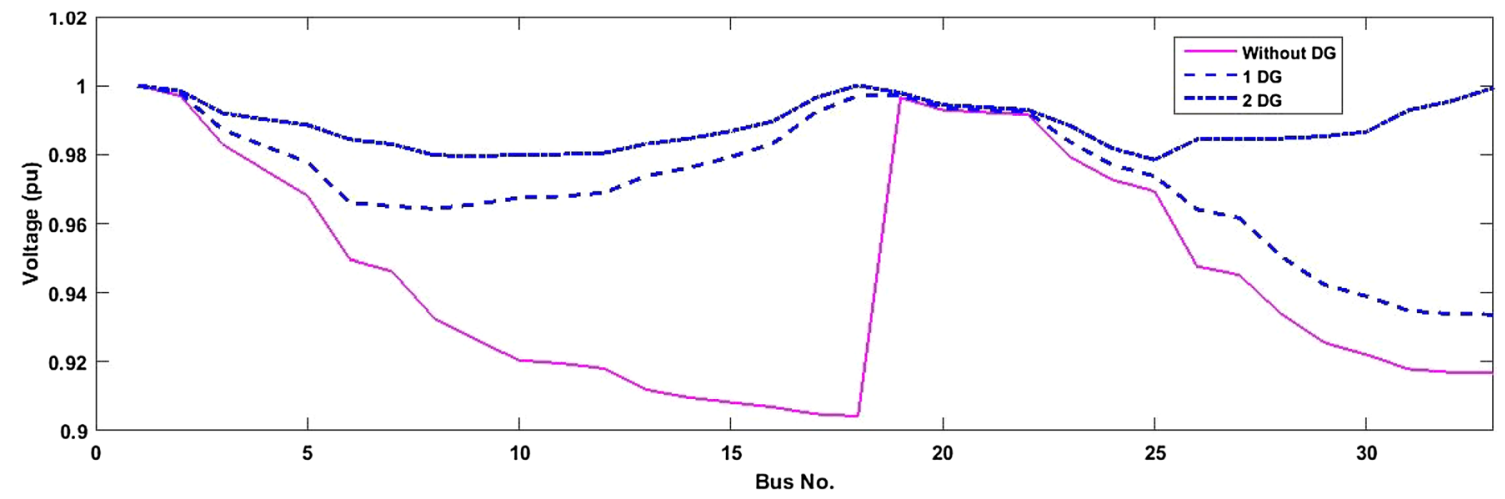

Fig. 7 Voltage profile of 33-bus RDS with and without DG

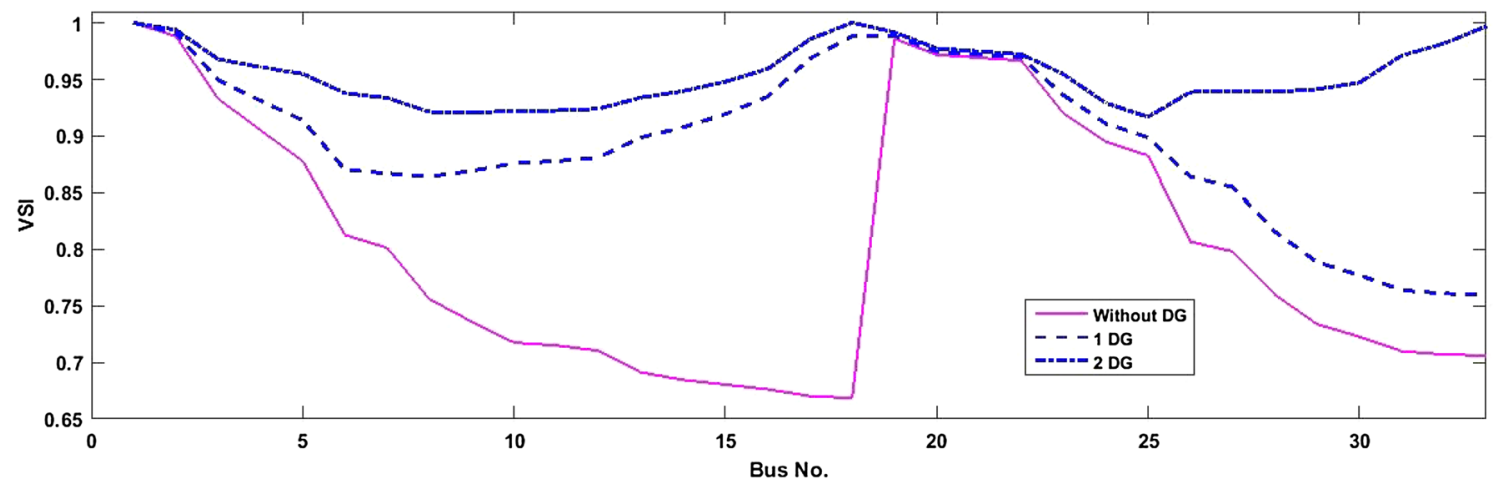

Fig. 8 Variation of VSI for 33-bus RDS with and without DG 


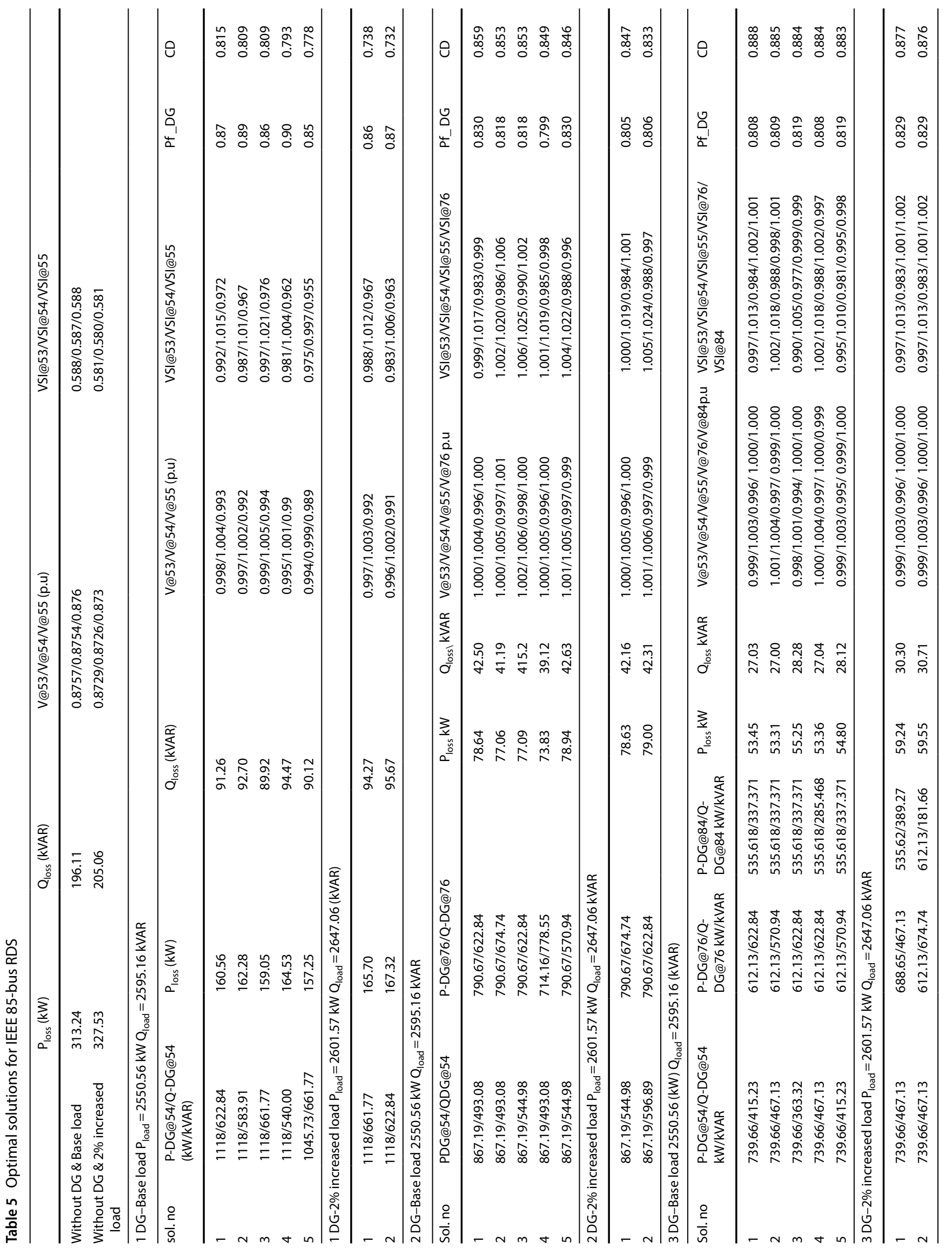




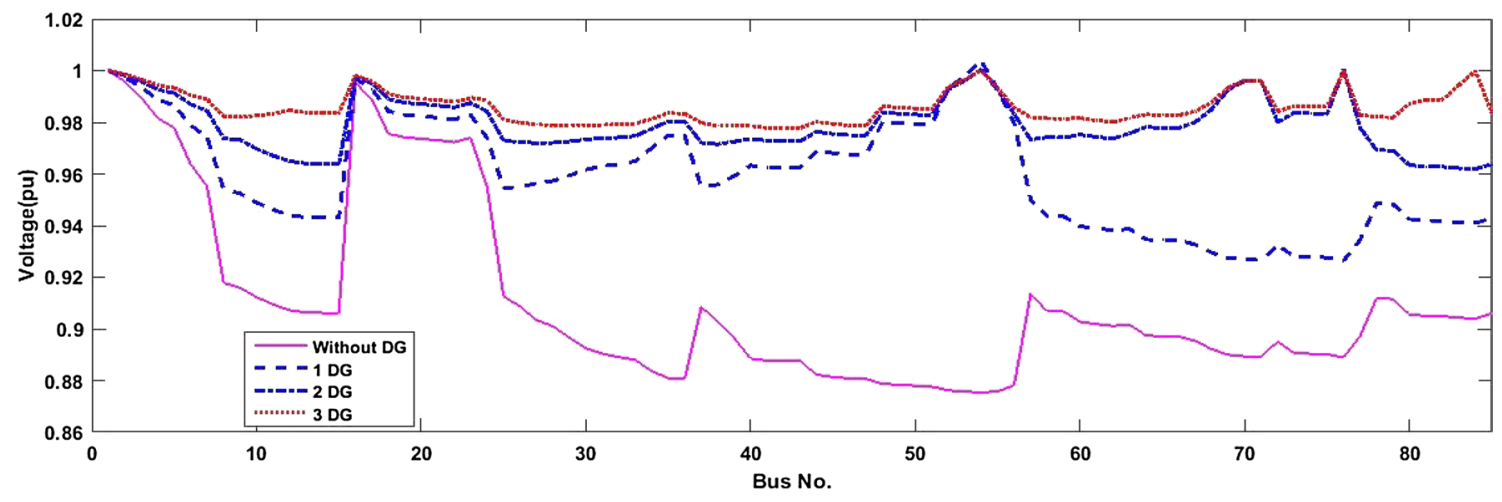

Fig. 9 Voltage profile of 85-bus RDS with and without DG

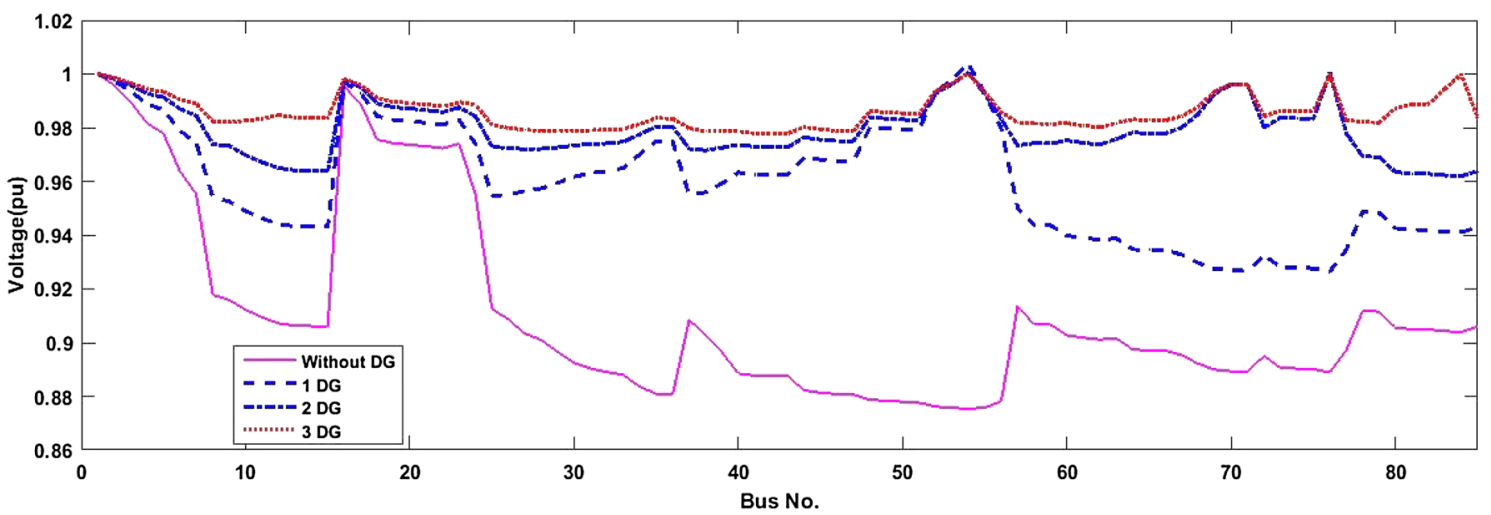

Fig. 10 Variation of VSI for 85-bus RDS with and without DG

higher than first solution. Accordingly ID of $\mathrm{P}_{\text {loss, }} \mathrm{Q}_{\text {loss' }}$ V@16, V@17, VSI@16 and VSI@17 for fifth solution is higher than that of first solution. However V@18 and VSI@18 of fifth solution deviate from target value of 1 which results in lesser ID values. ID of V@18,VSI@18 and pf_DG of first solution is higher than that of fifth solution. Hence first solution has highest CD. Investigator can choose the optimal solution as per requirement. For instance, if it is required to have higher pf_DG, then second optimal solution which have DG power factor of 0.97 may be selected.

Optimal size of DG for $2 \%$ increase in load can be found by setting the $P_{\text {load }}$ and $Q_{\text {load }}$ to their third levels. Table 4 shows first 2 optimal solutions when base load is increased by $2 \%$ and 1 DG is placed.

\subsubsection{Two DG placement}

For second DG placement next candidate bus having the lowest VSI after 1 DG placement is to be identified. Using MATLAB program VSI values at all the buses are recalculated after 1 DG placement. It is found that bus 33 has the lowest VSI value.
Second DG is placed at bus 33. In case of 2 DG placement there would be 6 input factors of different level values. The results obtained are given in Table 4. The $P_{\text {loss }}$ and $\mathrm{Q}_{\text {loss }}$ are reduced to $54.25 \mathrm{~kW}$ and $43.81 \mathrm{kVAR}$ respectively.Table 4 shows first 2 optimal solutions when base load is increased by $2 \%$ and 2 DG are placed. Voltages at weak buses have improved significantly. The voltage profile as well as VSI variation of IEEE 33, with and without DG, are shown in Fig. 7 and Figure 8.The voltage and VSI values of the first optimal solution shown in Table 4 are used in Figs. 7 and 8.

\subsection{IEEE 85-bus RDS}

TDFA is implemented for estimating optimal DG sizes for IEEE 85-bus RDS in case of 1 DG, 2 DG and 3 DG placement by following the same procedure. In case of 3 DG placement there would be 8 input factors of different level values and 13 responses have been simultaneously optimized. The results obtained are given in Table 5 .

$\mathrm{P}_{\text {loss }}$ is reduced to $160.56 \mathrm{~kW}, 78.64 \mathrm{~kW}$ and $53.45 \mathrm{~kW}$ while $\mathrm{Q}_{\text {loss }}$ is reduced to $91.26 \mathrm{kVAR}, 42.50 \mathrm{kVAR}$ and 27.03 kVAR for 1 DG, 2 DG and 3 DG placement resp. The 


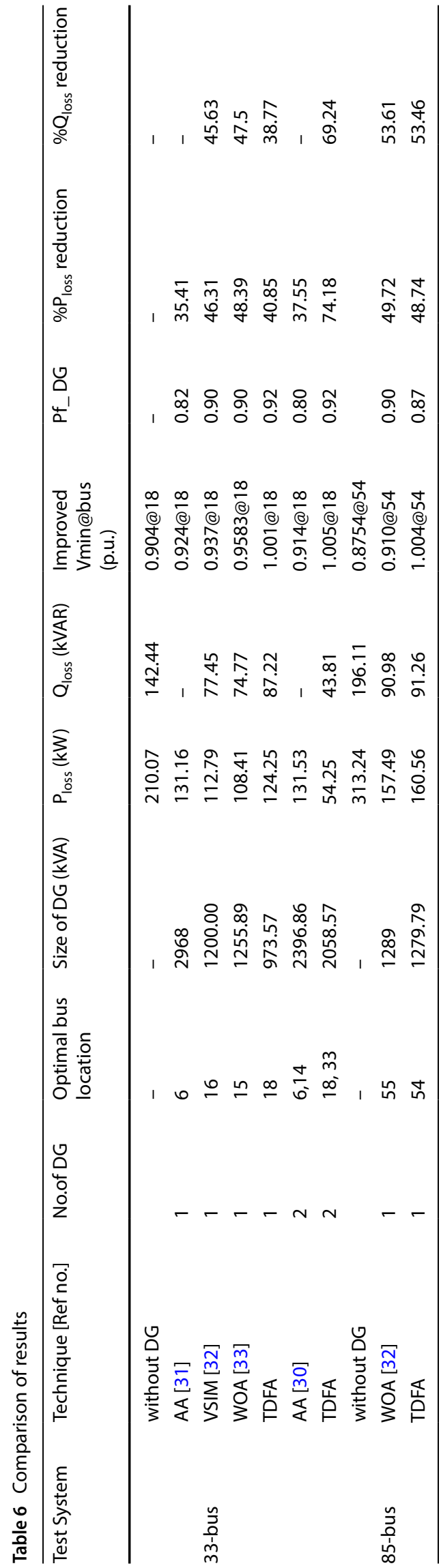

voltage profiles as well as VSI variation of IEEE 85 RDS, with and without DG, are shown in Figs. 9 and 10. The voltage and VSI values of the first optimal solution shown in Table 5 are used in Figs. 9 and 10.

\section{Comparison of results}

Comparison of TDFA solutions with results obtained by other techniques is carried out. Authors [31] have used novel Analytical Approach (AA) for minimizing the loss associated with the active and reactive components of DG branch current. This approach is not applicable for unbalanced and meshed distribution system. TDFA has no such constraints. In [32] comparison of four methods for optimally allocating DG is presented. One of those methods is Voltage Sensitivity Index Method [VSIM]. Authors have emphasized that losses can be reduced significantly with reactive power management of DG. Whale Optimization Algorithm (WOA) [33], a novel heuristic algorithm is used to estimate optimal DG size. Authors have computed the optimal size of DGs at different power factors to reduce the power losses of the distribution system and to enhance the voltage profile of the system. However results of heuristic method are not reproducible. The above mentioned techniques are used for comparing proposed approach. None of these techniques offer multiple near optimal solutions or have ability to optimize nearly thousand objectives simultaneously. Table 6 shows the comparison of results IEEE 33-bus RDS as well as IEEE 85 -bus RDS. The first optimal solution given in Tables 4 and 5 is used for comparison. It can be observed that voltage improvement by proposed technique is superior than obtained by any of other technique. It should be noted that in all of the first five optimal solutions shown in Tables 4 and 5 for IEEE 33-bus RDS and 85 -bus respectively Vmin is significantly improved.

\section{Conclusion}

In this paper optimal DG sizing is carried out by applying an extremely robust statistical tool, Taguchi Desirability Function Analysis (TDFA) for single as well as multiple DG units. Application of TDFA for optimal sizing of DG is not cited in the literature. The salient features of TDFA are the skillful handling of simultaneous optimization involving a large no. of objectives for complex system and its ability to produce multiple optimal solutions. In this paper more than nine objectives have been simultaneously optimized viz. minimization of reactive power losses $\left(\mathrm{Q}_{\text {loss }}\right)$, improving voltages of various weak buses, improving the Voltage Stability Index (VSI) at various weak buses and improving the 
power factor of DG (pf_DG).Using TDFA optimal DG size can be found for various load conditions. This approach is tested on IEEE 33 and IEEE 85-bus RDS. Comparison of TDFA results with results obtained by implementation of other optimization techniques is carried out. TFDA can be extended to larger bus systems and nearly thousand objectives can be optimized simultaneously.

\section{Compliance with ethical standards}

Conflict of interest On behalf of all authors, the corresponding author states that there is no conflict of interest.

\section{References}

1. Manas M, Saikia BJ, Baruah DC (2018) Optimal Distributed Generator Sizing and Placement by Analytical Method and Fuzzy Expert System: a Case Study in Tezpur University, India. Technol Econ Smart Grids Sustain Energy. https://doi.org/10.1007/s4086 6-018-0038-9

2. Afkousi-Paqaleh $M$, Abbaspour-Tehrani FA, Rashidinejad M (2010) Distributed generation placement for congestion management considering economic and financial issues. Electr Eng 92:193-201. https://doi.org/10.1007/s00202-010-0175-1

3. Rueda-Medina AC, Franco JF, Rider MJ, Padilha-Feltrin A, Romero $R$ (2013) A mixed-integer linear programming approach for optimal type, size and allocation of distributed generation in radial distribution systems. Electr Power Syst Res 97:133-143

4. Al Abri RS, El-Saadany EF, Atwa YM (2013) Optimal placement and sizing method to improve the voltage stability Margin in a Distribution System Using distributed generation. IEEE Trans Power Syst 28(1):326-334

5. Kayal P, Chanda CK (2013) A simple and fast approach for allocation and size evaluation of distributed generation. Int J Energy Environ Eng 4(1):7

6. Taher SA, Karimi MH (2014) Optimal reconfiguration and DG allocation in balanced and unbalanced distribution systems. Ain Shams Eng J 5(3):735-749. https://doi.org/10.1016/j. asej.2014.03.009

7. El-Ela AAA, El-Sehiemy RA, Abbas AS (2018) Optimal placement and sizing of distributed generation and capacitor banks in distribution systems using water cycle algorithm. IEEE Syst J. https ://doi.org/10.1109/jsyst.2018.2796847

8. Jain N, Singh SN, Srivastava SC (2014) PSO based placement of multiple wind DGs and capacitors utilizing probabilistic load flow model. Swarm Evol Comput 19:15-24

9. Nayanatara C, Baskaran J, Kothari DP (2016) Hybrid optimization implemented for distributed generation parameters in a power system network. Electr Power Energy Syst 78:690-699

10. Mohammadi M, Mehdi N (2013) Optimal placement of multitypes DG as independent private sector under pool/hybrid power market using GA-based Tabu Search method. Int J Electr Power Energy Syst 51:43-53

11. Dixit M, Kundu P, Jariwala HR (2017) Integration of distributed generation for assessment of distribution system reliability considering power loss, voltage stability and voltage deviation. Energy Syst. https://doi.org/10.1007/s12667-017-0248-6

12. Bala R, Ghosh S (2017) Optimal position and rating of DG in distribution networks by $A B C-C S$ from load flow solutions illustrated by fuzzy-PSO. Neural Comput \& Appl. https://doi. org/10.1007/s00521-017-3084-7

13. Ali ES, Abd Elazim SM, Abdelaziz AY (2016) Optimal allocation and sizing of renewable distributed generation using ant lion optimization algorithm. Electr Eng 1:1. https://doi.org/10.1007/ s00202-016-0477-z

14. Kefayat M, Ara Lashkar A, Nabavi Niaki SA (2015) A hybrid of ant colony optimization and artificial bee colony algorithm for probabilistic optimal placement and sizing of distributed Generation. Energy Convers Manag 92:149-161

15. Sultana S, Roy PK (2016) Krill herd algorithm for optimal location of distributed generator inradial distribution system. Appl Soft Comput 40:391-404

16. Mitra J,Vallem MR, Singh C (2016) Optimal deployment of distributed generation using a reliability criterion..IEEE Trans Industry Appl 52(3):1989 - 1997

17. Salmasnia A, Bashiri M (2015) A new desirability function-based method for correlated multiple response optimization. Int J Adv Manuf Technol 76:1047-1062. https://doi.org/10.1007/s0017 0-014-6265-x

18. Lin H, Su C, Wang C, Chang B, Juang R (2012) Parameter optimization of continuous sputtering process based on Taguchi methods, neural networks, desirability function, and genetic algorithms. Expert Syst Appl 39:12918-12925

19. Pandey RK, Panda SS (2013) Optimization of bone drilling using Taguchi methodology coupled with fuzzy based desirability function approach. J Intell Manuf. https://doi. org/10.1007/s10845-013-0844-9

20. Singh G, Pradhan MK, Verma A (2018) Multi Response optimization of injection moulding Process parameters to reduce cycle time and warpage. Mater Today Proc 5(2):8398-8405. https://doi.org/10.1016/j.matpr.2017.11.534

21. Hong Y, Lin F, Yu T (2016) Taguchi method-based probabilistic load flow studies considering uncertain renewables and loads. IET Renew Power Gener 10(2):221-227

22. Basetti V, Chandel AK (2015) Hybrid power system state estimation using Taguchi differential evolution algorithm. IET Sci Meas Technol 9(4):449-466. https://doi.org/10.1049/ietsm t.2014.0082

23. Montgomery DC (2006) Design and Analysis of Experiments. Wiley, New York

24. Roy RK (2010) A primer on the Taguchi method. Society of Manufacturing Engineers, Dearborn

25. Christensen Ronald (2015) Analysis of Variance, Design, and Regression: Linear Modeling for Unbalanced Data, 2nd edn. CRC Press, Taylor \& Franscis group, Boca Raton

26. Derringer $G$, Suich $R$ (1980) Simultaneous optimization of several response variables. J Qual Technol 12(4):214-219

27. Chakravorty M, Das D (2001) Voltage stability analysis of radial distribution networks. Int J Electr Power Energy Syst 23(2):129-133

28. IEEE 1547-2018 - IEEE standard for interconnection and interoperability of distributed energy resources with associated electric power systems interfaces. https://doi.org/10.1109/IEEES TD.2018.8332112

29. Suresh MCV, Belwin EJ (2018) Optimal DG placement for benefit maximization in distribution networks by using Dragonfly algorithm. Renewables 5:4. https://doi.org/10.1186/s4080 7-018-0050-7

30. Dinakara PR, Veera RT, Gowri TM (2018) Optimal renewable resources placement in distribution networks by combined power loss index and whale optimization algorithms. J Electr Syst Inf Technol 5(2):175-191. https://doi.org/10.1016/j.jesit .2017.05.006 
31. Viral R, Khatod DK (2015) An analytical approach for sizing and siting of DGs in balanced radial distribution networks for loss minimization. Int J Electr Power Energy Syst 67:191-201

32. Murthy VVSN, Kumar A (2013) Comparison of optimal DG allocation methods in radial distribution systems based on sensitivity approaches. Int J Electr Power Energy Syst 53(10):450-467
33. Reddy PDP, Reddy VCV, Manohar TG (2017) Whale optimization algorithm for optimal sizing of renewable resources for loss reduction in distribution systems. Renewables 4:3. https://doi. org/10.1186/s40807-017-0040-1

Publisher's Note Springer Nature remains neutral with regard to jurisdictional claims in published maps and institutional affiliations. 